Research Article

\title{
Greek Fiscal and Financial Data: More than Meets the Eye
}

\author{
Z. Georganta ${ }^{1,2 *}$ \\ ${ }^{1}$ University of Macedonia, Thessaloniki, Dept. of Economics and Social Sciences, Greece. \\ ${ }^{2}$ Member of the Hellenic Statistics Authority (EL.STAT.), Pireas, Attiki, Greece.
}

\begin{abstract}
Statistical data plays such a vital role in policy-making in all fields of human activity that its quality and reliability is a matter of human well-being. Within today's severe and unprecedented recession into which Greece seems steadily sinking, accuracy of national statistics has become as decisive for her survival as ever before. Our country's potential to rise above the present situation for the good of Greece's and eurozone citizens depends heavily on truthfully putting our statistics 'in order', something which is not currently happening. Fiscal and financial statistics may in general offer the greatest example of the principle 'garbage in, garbage out'. The issue is that users cannot usually assess the presence of garbage simply by reading the press releases, while at the same time they are suffering from the deleterious effects of the wrong-data. This paper uses extensively the concept-mapping approach to investigate basic reliability issues of Greece's fiscal and financial statistics. The statistical location of the deficit and debt items is sketched out within the European System of Accounts and five data reliability issues are identified. The paper is concluded with proposals on two fundamental reforms required to enable Greek statistics to serve the public good.
\end{abstract}

Keywords: Fiscal statistics, financial statistics, Greek Statistical System

\section{Introduction}

It seems that particularly in our country a major part of the academic community has traditionally considered that statistical data is a side-issue, that data collection, classification, presentation and in general, data generation and data management is a side-line work, a routine of second priority. It appears as if being scientific is required only when data is used for the application of advanced and sexylooking mathematical, statistical and econometric models to arrive most probably to a publishable academic paper. However, concentration on statistical inference without having previously paid attention to data collection and measurement issues, is a characteristic of scientific narrowmindedness. Great progress has been achieved regarding the statistical and econometric techniques, but this progress is lost if it is not applied to truthful and reliable data. Statistics is nothing less than the cosmos asking to be explained by the scientists whose conclusions are used by governments in order to devise policies for people's well-being.

Questions are asked in conferences about data quality and one of the most frequent responses is summed-up to "we either use the available data or we do not do research". This is a really cozy answer: it is in essence a covering up of using unreliable data. However, behind this superficial response lies the truth of the Greek situation: deep unhappiness of the Greek academic community with their governmental intervention to stifle any effort to improve data quality and objectivity. Thus, more often than not, data inefficiencies, lack of reliability and inaccuracies have made our job difficult, impossible or quite frequently dishonest. Consequently, Greek people are provided with methodically misleading findings. During the last 20 years, or so, economic statisticians and econometricians have been keen on data improvements. Unfortunately, such scientific ambitions have been strangled in Greece by governmental interference, exactly as it has happened with Greece's competitiveness, lively described in the study of Monitor Company (1993), notably stamped as "confidential" [1].

Because statistics plays a vital role in policy-making, gathering and managing statistics requires a two-fold principle: honesty and competence. If statistics is to serve the public $\operatorname{good}^{1}[2]$, the above two fold principle is conditio sine qua non. We should always remember the words of Zvi Griliches, the unforgettable late Harvard Professor of Applied Econometrics, who used to say that the measurement of socio-economic phenomena, the formulated measurement frameworks, the statistical methodologies, all seem to depend heavily on the quality and objectivity of our data.

The position of this paper is that: first, the well-known 'Greek Statistics' issue remains sadly intact today in spite of the well-celebrated new Statistics Law 3832/2010 establishing the independence of ELSTAT, and second, the 
numbers provided by Eurostat, the European Statistics Department, for Greece's deficit and debt do not have a transparent scientific foundation. Within this context, it is noted that Greece is not the only one who has "massaged" her data in the past: while presenting the new British Budget last year, George Osborn, the British Finance Minister, committed himself that he will never use data which have undergone "massage" as it was happening in the past. It is recognized that after the explosion of economic crisis in Europe, there has been a pan-European effort to give out honest data which depicts the true situation without microscopic footnotes, especially in relation to national debt and deficit, on which the welfare of European people heavily depends.

The purpose of this paper is three-fold: First, to present the location in space, but also in time sequence, of the stocks and flows of Greece's macro-economy within the European System of Accounts, [3] framework by using the conceptmapping approach [4]. Second, to dispute Eurostat on Greece's General Government debt and deficit numbers. Third, to propose ways to combat the data problems on the basis of morals which require to truthfully and transparently apply the Eurostat Manual on Government Deficit and Debt regulations [5]. The paper is structured in five sections: the second section describes the stocks and flow data as a constituent element of Greece's National Accounts within the ESA95 framework. This section aims at making clear the link between the real economy variables and the national deficit/debt data. The third section provides a review of identified problems regarding the officially published deficit/debt data. The fourth section proposes ways to combat the problems on the basis of economic morals for the common good. Finally, the last section concludes the paper.

\section{Fiscal and Financial Data as a Constituent Part of the ESA95}

\subsection{A Brief Description of ESA95}

The ESA95 is an internationally compatible accounting framework for the description of social and economic statistics of the European Union (EU) and its member states. It has been built according to macro-economic theory which distinguishes five basic economic processes: (1) production, (2) income generation, (3) income distribution, (4) use of income, and (5) capital formation or the so called accumulation process. Schema 1 gives a synoptic description of the ESA95 from which we can get a first visualization of the interconnections between the real economy and financial procedures.

Economic processes are sequentially connected. As we can see in Schema 1, the National Accounts (NA), which can be annual or quarterly and, at the same time, national or regional, contain three broad-spectrum components:

(1) institutional sectors,

(2) macroeconomic processes and their corresponding financial procedures, and

(3) economic sector accounts.

All three components intermingle in order to arrive at a consistently systemic picture of our national economy. The four institutional sectors in Schema 1 are four aggregate groups of subjects of economic activity described in the NA. Each aggregate group includes economic subjects which exhibit similar behavior. Thus,

(1) The household sector covers individuals acting as consumers, as well as entrepreneurs, but without separate business entities. This category is usually merged with the non-profit institutions serving households.

(2) The non-financial corporations covers enterprises which produce goods and non-financial services sold on the market.

(3) The sector of financial corporations consists of all enterprises engaged in financial activities.

(4) The general government sector includes the central government, the state government, the local government, and the social security Funds.

Because, by definition, the NA consists in an accounting framework, a core broad-spectrum component is the economic sector accounts (SA), which record every transaction between the four aggregate economic subjects during an accounting period. At the same time, the SA cover all five macro-economic processes, which are financially portrayed in their corresponding balance sheets summarized in the NA component 'Financial procedures' in Schema 1.

SA are distinguished between Current Accounts and Accumulation Accounts. Current accounts are non-financial, or real-economy, accounts and include accounts for each one of the four institutional sectors, covering, at the same time, the four out of the five macro-economic processes (Schema 1). Similarly, accumulation accounts cover each one of the four institutional sectors, but include two accounts: (1) the capital account which is a real-economy - i.e. a nonfinancial - account describing the fifth macro-economic process, namely, the capital formation process, and (2) the financial account (related to the 'financial procedures' item in Schema 1), which sums up the corresponding financial balance sheets of all five macro-economic processes for each institutional sector, as one would expect in any complete accounting system.

Institutional Sectors and Economic Sectors

Although it is clear in Schema 1, however, a few words may be helpful concerning the distinction between the concepts of 'institutional sectors' and 'economic sectors': the former refers to economic subjects and the latter refers to economic activities, which, within the ESA95, are classified according to the so called NACE code (Statistical Classification of Economic Activities in the European Community).At the most aggregate level of NACE revision 1.1, six categories of economic activity are identified: (1) agriculture, hunting and fishing; (2) manufacturing and energy; (3) construction; (4) trade, transport and communication services; (5) business and financial services; and (6) other services.

\subsection{The Link Between the Financial Economy and the Real Economy in ESA95}

As said in subsection 2.1, non-financial transactions during a certain period are summarized by their corresponding financial balance sheets. It is noted that these transactions are grouped into various categories which have a distinct economic meaning, such as wages and salaries. Also, various aggregate items are broken down according to specific classifications. For example, consumption expenditure is distinguished in a number of categories according to purpose.

Each non-financial transaction is recorded as an increase in the resources of a certain sector and an increase in the uses of another sector. For example, the resources side of the transaction category 'taxes on products' records the amounts 
of taxes-on-products receivable by different economic sectors and different institutional sectors. The uses side shows taxes-on-products payable. For each type of transaction, total resources of all sectors equal total uses. Each account leads to a balancing item which on the one hand is meaningful according to economic theory, and on the other hand, it is equal to total resources minus total uses, or total revenues minus total expenditures. Such balancing items, like GDP (Gross Domestic Product), GNI (Gross National Income), DI (Disposable Income), S (saving), C_N_W (change in net worth), are important economic indicators and they are carried over to the next account within the sequence of accounts as shown in Schema 2. So, in Schema 2 we can see that the macro-economic processes of Schema 1 are described by corresponding macroeconomic accounts linked to each other by their balancing items.

As shown in Schema 2, the production account describes the production process. It shows the value added for all domestic economic activity sectors and industries. The value added is either gross or net depending on whether it includes the fixed capital consumption (depreciation or decrease in the value of fixed assets like computers, buildings, machinery, and so on, due to usage or technological progress). The sum of gross value added over all domestic economic activity, Gross Domestic Product (GDP), is the balancing item of the production account.

Domestic product is then carried over as a resource to the generation-of-income account. Its balancing item, GOS (Gross Operating Surplus) consists of mixed income, which accrues to self-employed households, and operating surplus, which accrues to corporations. It is noted that income generated in production is called 'primary income' and it is described by the primary distribution-of- income account. The primary income is distributed as wages and salaries, taxes, and property income. For the economy as a whole, this adds up to Gross National Income (GNI) and differs from GDP in what is called 'net primary income from abroad'. GNI is the balancing item of this account and it is carried over as a resource to the next account, the secondary distribution-of-income account.

The secondary distribution-of- income account shows how the primary income is transformed into disposable income due to various transfers like taxes, and social benefits. Gross disposable income (GDI) is the balancing item of this account and it is carried over to use-ofdisposable-income account, which shows how disposable income is used, i.e. spent on consumption or saved. Its balancing item is NS (net saving, positive or negative) and it is carried over to the capital accounts.

The capital accounts are non-financial accounts. They include two major components: (1) the change-in-net-worth account, which nets saving (the balancing item of the use-ofdisposable-income account) and net capital transfers, and, (2) the acquisition of non-financial assets account, which includes investment, change in inventories and any net acquisition of other fixed assets, like land. The balancing item, C_N_W (change in net worth), of the first capital account is carried over to the second capital account, whose balancing item is net lending (+)/net borrowing (-) and it has been coded B9 in ESA95. B9 closes the sequence of the non-financial accounts. B9 is the total economy's deficit or surplus, defined by the difference between revenues and expenditures. The way B9 is financed is shown in the financial accounts.
The financial accounts record the net acquisition of financial assets and the net incurrence of liabilities. Because every non-financial transaction is mirrored by a financial transaction, the balancing item of the non-financial accounts is equal to the balancing item of the financial accounts. So, it is the national deficit/surplus which provides the link between the financial and non- financial part of the National Accounts according to ESA95.

This subsection has described ESA95, which constitutes the framework within which each EU member state is obliged to compile her National Accounts (NA) on the basis of a predefined classification system, structure of accounts and a set of rules such as the valuation rule. As we saw in Schema 2, there are three interrelated vital groups of NA elements: (1) institutional sectors, (2) macro-economic processes, and (3) economic sector accounts. Since institutional sectors are the subjects of macro-economic activity, they constitute the decisive force of the national economy. Among the four of them, the general government (GG), and especially the central government, is the major institutional sector whose policy decisions have direct effects on all the other three sectors. The star polygons in Schema 2 represents the national debt which has a question mark to denote that there is no specific definition of debt in ESA95, but only general provisions about the delineation of the GG sector, the financial liabilities and their valuation rules (see Eurostat Manual on Government Deficit and Debt, 2002, section V1, p.196; Manual on Government Deficit and Debt, Implementation of ESA95, 2010, section VIII.2.1, p.305).We could say that debt equals the stock of all liabilities outstanding in a certain time period.

\subsection{The Contribution of the Institutional Sectors to National Economy}

The institutional sectors make different contributions to national economy. Chart 1 shows the contribution of each institutional sector to basic macroeconomic magnitudes for the period 2000-2009 on average. Table 1 shows the numerical contributions of the four institutional sectors to total economy including the corresponding magnitudes for the euro area, and also, for comparison purposes, Table 1 includes corresponding contributions of a small and a big Mediterranean country, namely, Portugal and Spain. Figures 1-3 shed more light on Chart 1 because they refer to individual years during the period 2000-2009.

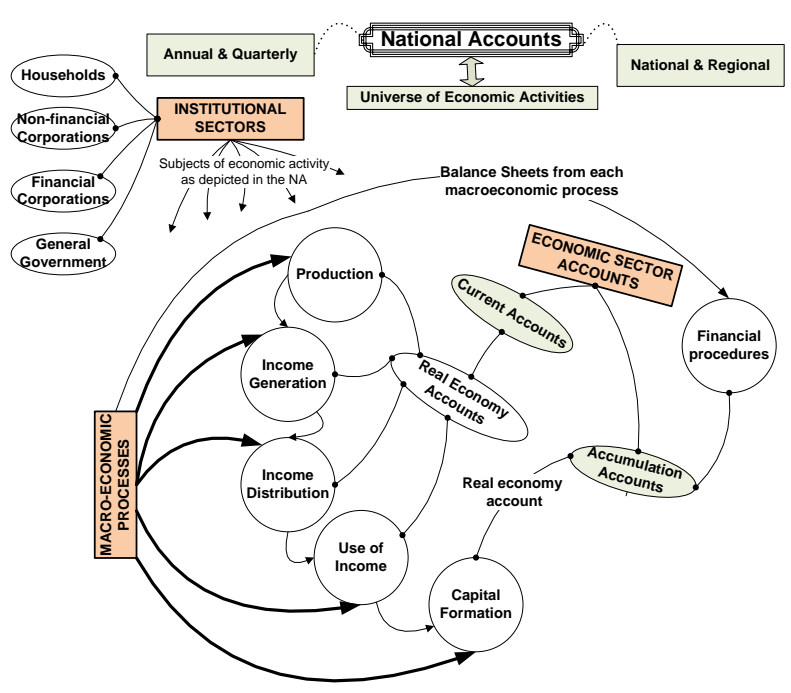


Schema 1. The National Accounts Sequence of their Basic Building Blocks according to ESA95

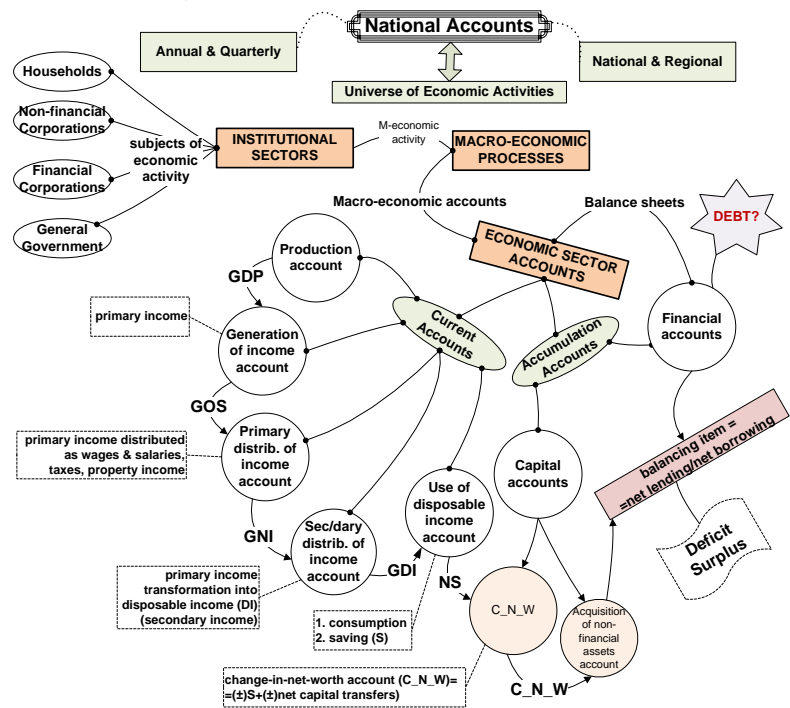

Schema 2. The National Accounts Sequential Interconnections according to ESA95

The notation of the macro variables on the perpendicular axis is the following: DEF denotes the deficit/surplus, GDI is the Gross Disposable Income, GS is Gross Saving, GVA is the Gross Value Added, I is Fixed Capital Formation, NDI is the Net Disposable Income and NNI is the Net National Income. In Chart 1 , the negative portions show negative contribution of the respective institutional sectors to the selected macro variables. Thus, regarding the variable DEF, the financial and non-financial corporations have reduced Greece's deficit, while households and general government have increased it. Regarding national savings, GS, the nonfinancial corporations have greatly increased them, while the general government has hugely decreased it. We can also see that households have on average greatly contributed to national production and investment.

By combining Chart 1 with Figures 1 and 2, we can see that variable $\mathrm{DEF}$ for the whole economy is always negative during the last decade, while variable GS is positive but declining since 2004-2005. Net saving of the total economy (Figure 3) shows a negative development during the whole period, while the financial and non-financial corporations have a positive contribution to net saving during the whole period.

Thus, by looking at Table 1, households and general government contribute to the increase of total economy deficit by $77 \%$ and $61 \%$ respectively. The corresponding contributions to total economy's deficit are $-30 \%$ and $52 \%$ for Portugal, and $-15 \%$ and $29 \%$ for Spain. This means that Greece's households increase by $77 \%$ the total economy's deficit, while the Portuguese and Spanish households decrease it by $30 \%$ and $15 \%$ respectively. The general government increases total economy's deficit for all three countries - Greece, Portugal and Spain - by 77, 52 and 29 per cent respectively.

Total economy's gross saving is reduced more than $93 \%$ by the activities of general government in Greece and 15\% in Portugal, while in Spain the general government increases total economy's gross saving by $14 \%$. Portugal and Spain have positive net saving. For Greece, we observe some extremely high negative contributions to total economy's net saving by households and government $(462 \%$ and $456 \%$ respectively). Non-financial corporations seem to increase total economy's net saving by almost $680 \%$.
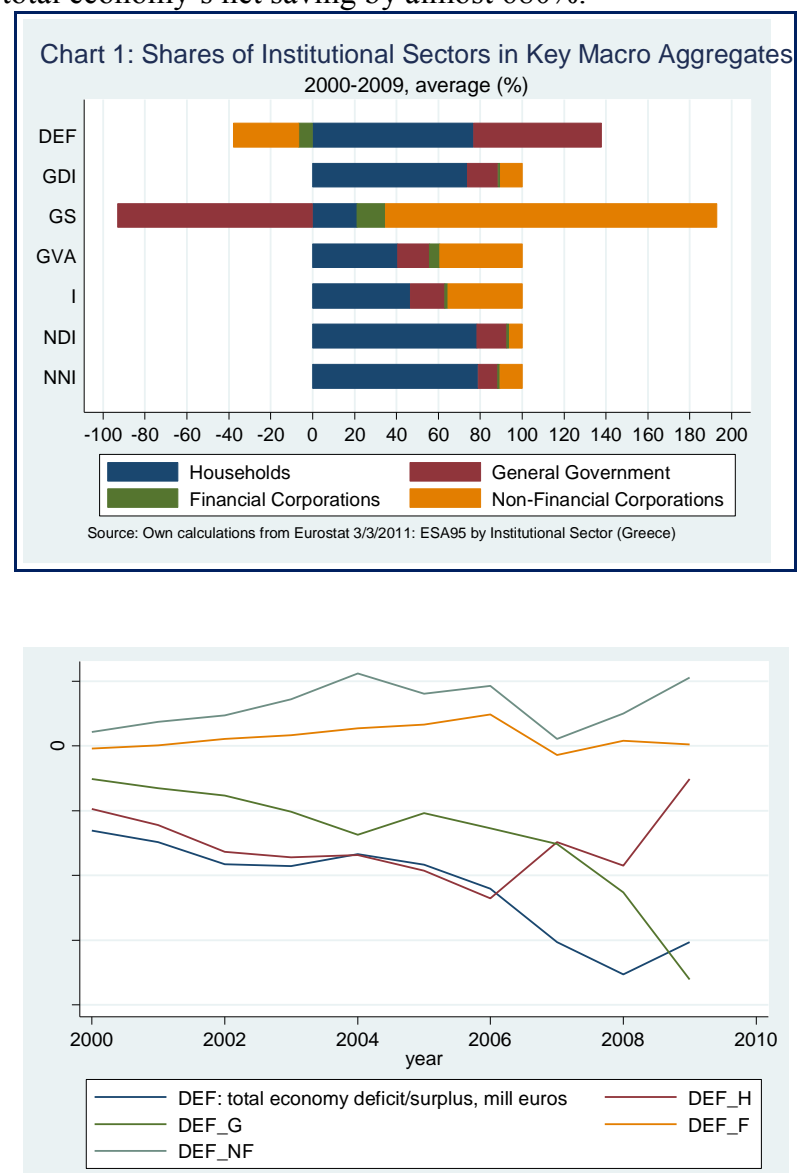

Fig. 1: Deficit of total economy and institutional sectors (2000-2009)

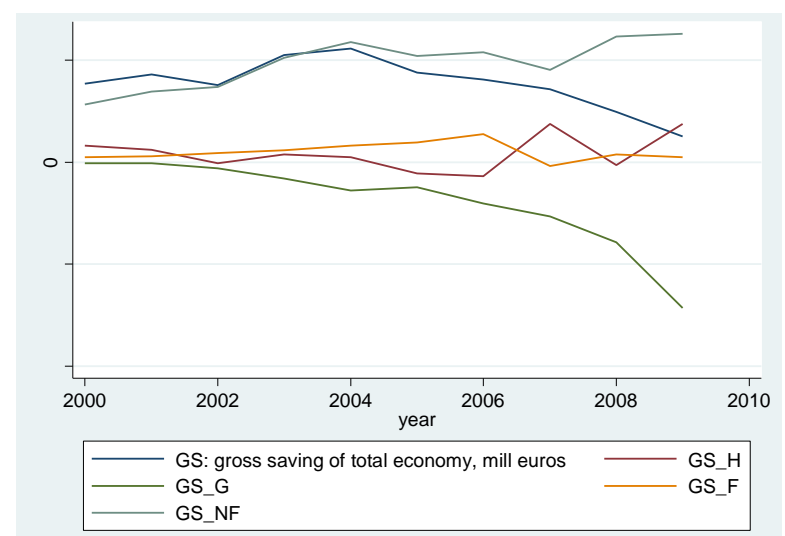

Fig. 2. Gross Saving of total economy and institutional sectors (20002009) 
Table 1: Shares of Institutional Sectors in Key Macro Aggregates in euro area, Greece, Portugal and Spain (20002009 average)

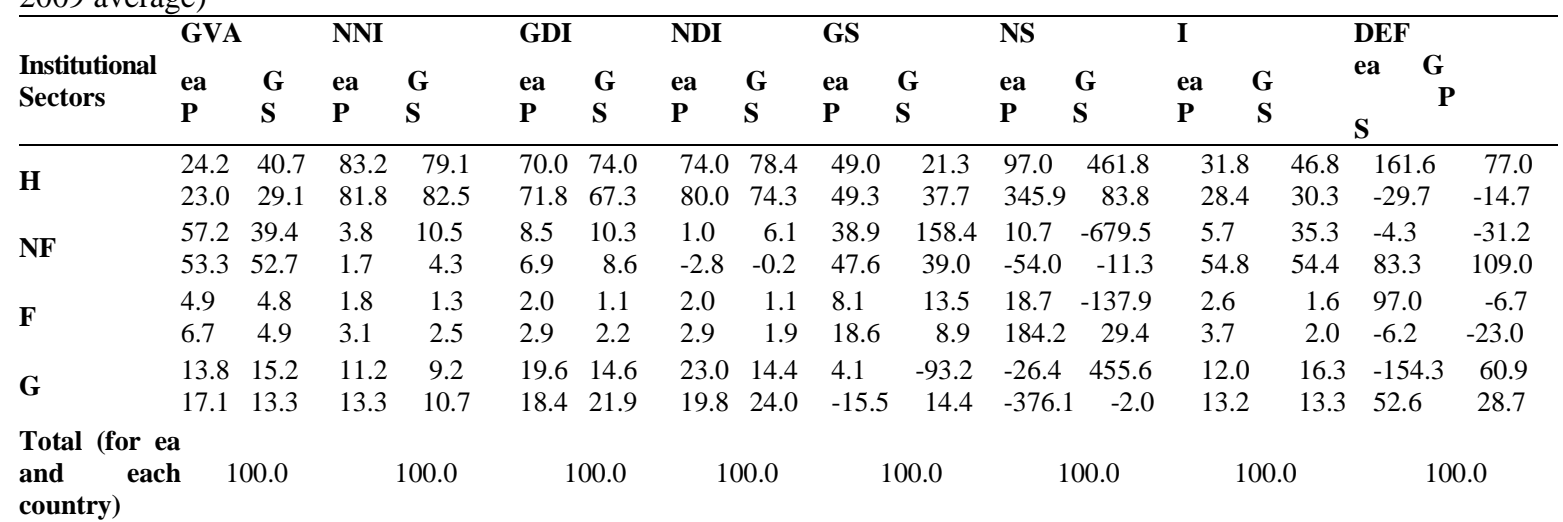

Source: Own calculations based on individual country Tables for 1999 to 2009, Annual Accounts (ESA95) by Institutional Sector, Eurostat. (Greece 3-3-2011, Portugal 31-3-2011, Spain 4-10-2010)

Notation: ea: euro area, G: Greece, P: Portugal, S: Spain

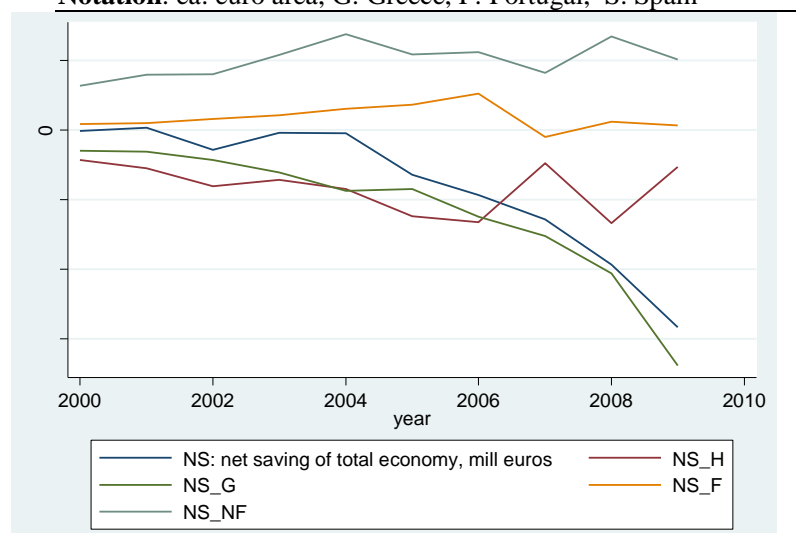

Fig. 3. Net Saving of total economy and institutional sectors (20002009)

In Table 1 we see some very strange numbers for Greece: (1) The columns GS, NS and DEF exhibit very different magnitudes between Greece and ea, Portugal and Spain. (2) How can it be that, for example, the non-financial corporations would contribute by $158.4 \%$ to GS (gross saving) and by $-679.5 \%$ to NS (net saving). Taking into account the data presented by Georganta (23 March 2011) [6] which show the irrationality of present economic policies in Greece, basically based on probably bad deficit and debt data, it is a matter of urgency that the numbers of Table 1 have to be explained and further investigated for probable serious misreporting.

\section{REVIEW OF IDENTIFIED PROBLEMS}

General government (GG) in Greece includes three entities: (1) Central government, (2) Local government, and (3) Social security funds. The purpose of GG is basically two-fold: first, to produce non-market services (education, health care, defense, policing, etc.), and second, to redistribute income. As happens with the other three institutional sectors, GG functions within the general framework of Schema 2. Of course, each institutional sector has its own particularities regarding structure and rules relating to its accounts. For example, the valuation of GG output is different from the valuation of private corporations who aim at profit maximization.

The four major financial indicators for $G G$ are the following: (1) GG deficit, (2) GG debt, (3) GG expenditure, and (4) GG revenue (taxes and compulsory social contributions). GG deficit is defined as the negative difference between revenue and expenditure and it is equal to the GG part of item B9 (net lending/net borrowing) discussed in the subsection 2.2. As explained, also in subsection 2.2, there is no specific definition of GG debt in ESA95. The only definition provided in ESA95 is that the stock of government debt equals the sum of all liabilities of the GG sector at market values with the additional note "where applicable" (ESA95, 2010 edition). Consequently, the accurate delineation of GG, which is a condition sine qua non for a reliable calculation of debt, is considerably left with the National Statistics Authority to decide.

In other words, the size of all the above indicators for Greece, as it happens with the rest of EU countries, depends on the scope of the GG sector as judged by ELSTAT. There 
is no doubt that all units representing the state, such as the Ministries, are included in the GG sector. But, what about the Public Power Corporation and the Greek Post Office, both of which have long exercised a public monopoly, are they part of the GG sector [7] ?

Knowing which entities is part of the GG sector is crucial for the reliable calculation of the public deficit and debt, and, of course, of a calculation that is internationally comparable. National accountants should pay particular attention on deciding which institutional units form part of the GG sector. Unfortunately, there are serious doubts - as we shall see later - whether such attention has been paid by those who since August $2010^{2}$ were made responsible for the calculation of Greece's public deficits. As we all know, the deficit numbers, especially for the year 2009, are behind the country's very recent ${ }^{3}$ woes, which are predicted to go on for decades to come.

\subsection{What the GG includes}

ESA95 have established a number of criteria for classifying resident entities (economic units, or subjects, or agents) to the GG sector. The classification of economic units is of utmost importance because the deficit and debt of units classified to GG add to the GG deficit and debt. Thus, national statisticians are required to determine whether the economic unit is,

1. an institutional unit,

2. a public institutional unit, and

3. a non-market public institutional unit

This subsection will give a brief picture of the really complex and multidisciplinary task at hand. As a general rule, the GG sector includes all institutional units which are public producers and at the same time they are non-market, i.e. they do not operate according to market forces (demand and supply). Schema 3 presents a synopsis of the type of units that the GG sector includes.

As we can see in Schema 3, the GG sector includes only public producers, who are either non-market institutional units, or non-institutional units who can operate as both, either non- market or market entities. This arrangement looks simple at first glance, but if we examine the meaning of all the concepts involved, we realize that deciding what units to include in the GG sectoris not a simple task; it requires extensive and time consuming research, as it can easily be understood by reading the Eurostat Manual on Government Deficit and Debt $(2002,2010)$.

\footnotetext{
${ }^{2}$ The new independent Hellenic Statistics Authority (EL.STAT.) started functioning on the $1^{\text {st }}$ of August 2010 as a seven-member Board, but in reality it has always been one man's, the chairman's, Authority.

${ }^{3}$ The newly calculated deficit numbers are the second blow against the country's trustworthiness after the outrageous massaging of its statistics in the recent past.
}

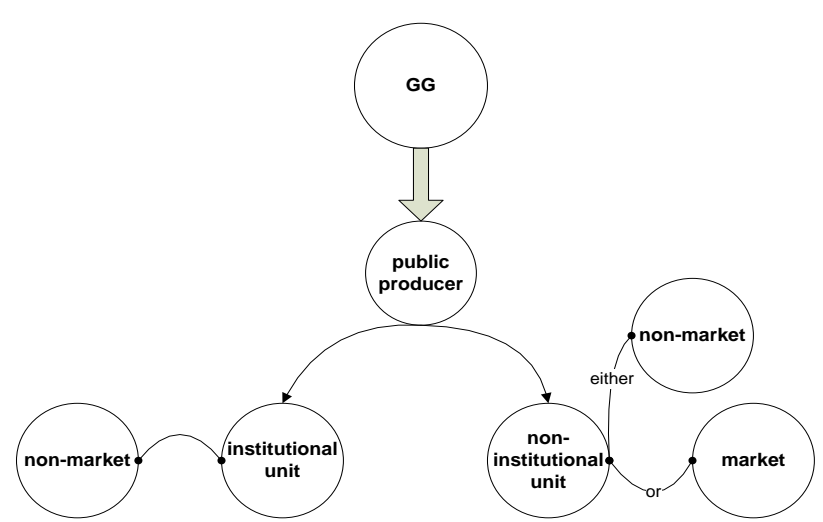

Schema 3. Types of units included in the GG sector

Schema 4 gives a synopsis of what an institutional unit is.

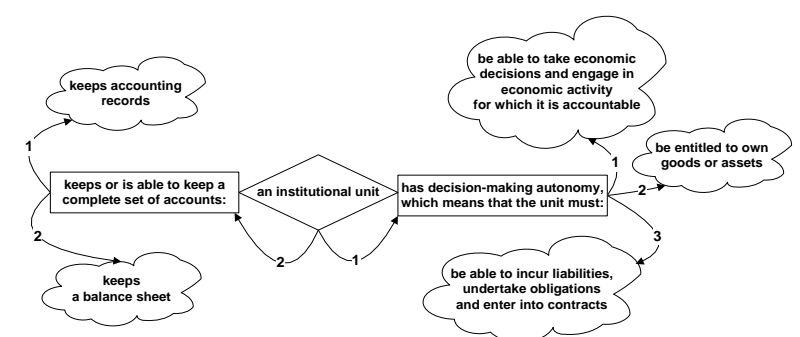

Schema 4. Basic features of an institutional unit

The second fundamental concept involved is that of a public producer, which requires that an economic unit has to be controlled by the general government. In its turn, the concept of control is defined as the ability to determine the general corporate policy or the unit's program by appointing appropriate managers "if necessary".

The third concept of a "market" unit involves the financing of the unit by its own sales of goods and services at economically significant prices. It is supposed that nonmarket producers provide most of their output to others free or at prices that are not economically significant. An economically significant price influences the amounts the producers are willing to supply and the amounts the purchasers wish to buy; in other words, the economically significant price is the one determined by the market forces of demand and supply.

Regarding the economically significant prices, ESA95 introduce the so called $50 \%$ additional criterion: economically significant prices are defined as prices that generate sales covering more than $50 \%$ of production costs. This criterion must be fulfilled over a range of years. Then the questions go on: how production costs are defined? What do "sales" include? The details of all the above concepts, including implementation exceptions and particularities for certain industries and individual units (e.g. hospitals and schools) are so numerous and tricky that deep knowledge of the national micro and macro economy is absolutely mandatory. For this reason, individual countries have put lengthy efforts to study their own economy and they have employed statisticians, accountants, legal experts and scientists from other fields to carefully examine which economic units are to be included in the GG sector, as well as in the other three institutional sectors. To my knowledge, there has been no such study in Greece, either by the 
Hellenic Statistics Authority staff, or by any other expert group.

\subsection{Summarizing the identified problems}

We have identified five serious problems which put in doubt the reliability of Greece's statistics for the country's deficit and debt. These problems are the following:

(1) Continuous change of numbers

Diagram 1 presents the contribution of each General Government subsector to the country's deficit.

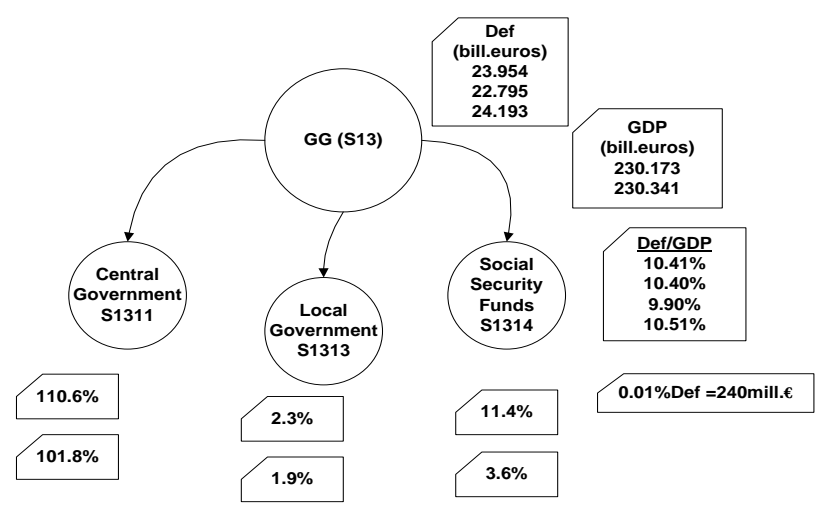

Diagram 1. Contribution of GG subsector to Greece's deficit, 2010
In Diagram 1 we can notice the different numbers for the same variable. Thus, for the Local Government's contribution to public deficit there are two numbers, $2.3 \%$ and $1.9 \%$. For the Social Security Funds contribution has also two numbers, $11.4 \%$ and $3.6 \%$. The same inconsistency happens with the rest of the figures reported in Diagram 1.

\section{(2) Perennial Half-finalization}

The following Table 2 includes the most recent data available in Eurostat's site about Greece's deficit and debt data (Eurostat, 13/4/2011) [8].

As we can see in Table 2, all figures (2007-2010) are characterized as half-finalized, contrary to what happens for the rest of European countries and contrary to Eurostat's well-known local-Press announcements that Greek data are now final, as well as reliable. Moreover, what actually was presented to the ELSTAT Board for approval (which was never given) were aggregate data as those in Table 2. How this data was compiled was never revealed at least until today that this paper is being written up. It is noted that the European Central Bank (May 2011, p.5) [9] reports the following: "After almost two decades of Excessive Deficit Procedures (EDP) missions to Greece led by Eurostat, as late as November 2010 Eurostat still expressed reservations on the quality of the data reported by Greece's Statistical Institute for 2009, on issues such as Social Security Funds' accounting, the classification of some public entities or the recording of off-market swaps."

Table 2: Eurostat's Table 1 on Greece's Deficit and Debt

Table 1: Reporting of government deficit/surplus and debt levels and provision of associated data

Member state: GREECE

Data are in millions EUR

Date: $13 / 04 / 2011$

Net borrowing (-)/ net lending (+)

General government

- Central government

- State government

- Local government

- Social security funds

ESA 95
Codes
EDP B.9
S.13
S.1311
S.1312
S.1313
S.1314
2007 half-finalized half-finalized half-finalized half-finalized

$\begin{array}{rrr}-23.121 & -36.306 & -24.193 \\ -23.391 & -35.640 & -26.754 \\ \mathrm{M} & \mathrm{M} & \mathrm{M} \\ -132 & -131 & -565 \\ 402 & -535 & 3.126\end{array}$

half-finalized half-finalized half-finalized half-finalized

\section{General government consolidated gross debt}

Level at nominal value outstanding at end of year By category:

Currency and deposits

Securities other than shares, exc. financial

Short-term

Long-term

Loans

Short-term

Long-term

General government expenditure on:

Gross fixed capital formation

Interest (consolidated)

p.m.: Interest (consolidated)

AF. 2

AF. 33

AF. 331

AF. 332

AF. 4

AF. 41

AF.42

P.51

EDP D.41

D.41 (uses)
239.364

693

194.500

1.625

192.875

44.171

555

43.616

7.642

10.002

10.678
262.318

298.706

1.477

728

216.324

5.496

210.828

45.266

292

44.974

8.540

11.696

11.750
252.923

10.820

242.103

44.306

1.513

42.793

7.111

11.986

12.328
328.588

1.005

252.473

9.121

243.352

75.110

2.756

72.354

6.367

12.832

12.594

Gross domestic product at current market prices

B. $1 * g$

227.074

236.917

235.017

230.173 


\section{(3) Non-availability of data}

As we can in the recently published (April 2011) EDP [7] Consolidated Inventory of sources and methods (p.4), financial statements are NA/NU (not available/not used) for the year 2009. The question is how the deficit and debt numbers were compiled without balance sheets and without profit and loss accounts. In spite of this the deficit for the crucial year 2009 was announced as equal to $15.4 \%$ the biggest in Europe. We refer to the reference in (3) above (report of the European Central Bank, May 2011) [9].

(4) Reclassification of public enterprises and other entities within the GG sector (S13)

In order to classify economic entities into the GG sector, which determines the deficit, statistical experts have to make sure that the criteria described in the above subsection 3.1 are satisfied. Given that these criteria form a whole system on which ELSTAT's judgment has to be founded before any official publication is made, ELSTAT and Eurostat should have stressed the need for carrying out relevant research and studies, which, notably, have never been carried out before. Instead of this, the chairman of ELSTAT together with Eurostat publish the deficit figures after having refused to listen to any different voices towards the right direction. It is well known that the announced of the deficit number for the year 2009 had a deleterious effect on Greece's socioeconomic policies. (See European Central Bank, May 2011) [9].

\section{(5) Strange numbers}

four of which had been appointed by the Greek Parliament after an open public call. This Board was supposed to secure the independence of Greece's official national statistics; it was to replace the governmental influence through the General Secretary of the Ministry of Finance who had been the head of the National Statistical Service of Greece up to that point in time. Moreover, the seven-member ELSTAT was to replace the subjectivity of one man's rule over the country's official statistics.

In spite of these apparently great national needs, the new 7member Authority was very soon replaced by its chairman and it was turned into a rubber stamp. By the beginning of October 2010 the six members of the Authority were "excommunicated".

Another problem desperately needing to be resolved relates to the structure of the Greek Statistical System (GSS): it has to be rationalized. GSS is very messed up: instead of separating the functions of the Hellenic Statistics Authority (ELSTAT) from an Office (or Institute) for National Statistics (the ex National Statistical Service of Greece which was Greece's single largest statistical producer), both functions were merged under one chairman without any network of National statistical experts despite the overabundance of internationally recognized Statisticians and Econometricians in the country.
In subsection 3.2 we have remarked the need for further investigation regarding certain numbers. Taking into account the Eurostat Manual on Sources and Methods (2011), as well as the Eurostat's Annual Accounts by Institutional Sector, Greece (2000-2009), we can observe huge "statistical discrepancies" between the items B9 and B9F (B9 in terms of financial accounts). Thus, for the crucial year 2009 we see a statistical discrepancy equal to $78 \%$ regarding the nonfinancial corporations, $372 \%$ regarding the financial corporations, $274 \%$ regarding the households including NPISH (Non-profit Institutions serving households).

\section{A Proposal Targetting The Public Good}

The basic most important change, which has to be institutionalized by implementation and not only by legislation, is the safeguarding of ELSTAT's independence, far from any influences, domestic or otherwise, in order to put an end to political manipulation of Greek statistics and rectify the country's reputation about the objectivity of its national data, especially in relation to its fiscal and financial numbers. What has actually happened during the last year or so is the following:

In August 2010, the newly independent Hellenic Statistics Authority (EL.STAT.) [10] started functioning under a 7-member Board of statistical experts,

\section{Concluding Remarks}

We all know the fiscal and financial problems facing the European countries threatening to demolish the world financial system. Deficit and debt data can be quite complicated and national particularities are correctly allowed to lapse into international and European regulations regarding the National Accounts' compilation. This paper has focused on three issues: First, the concise presentation of the location of deficit and debt statistics within the European System of Accounts (ESA95) by using a concept-map approach. Second, the identification of serious reliability problems regarding Greece's fiscal and financial data. Third, the formulation of basic proposals towards the solution of the Greek Statistics issue.

The basic problems are traced in the lack of independence of the Hellenic Statistics Authority and the structure of the Greek Statistical System. Of course, these problems are not unique in the statistics only, but are endemic in all spheres of the socio-economic structure of Greece, with her governments traditionally exercising almost absolutely stifling control on any individual or business creative effort by having promoted clientelism to its extreme form.

\section{References}

1. Monitor Company Strategy for a Competitive Greece, Ministry of Development, Greece (1993).

2. UK Statistics Authority Annual Report and Resource Accounts (2008/2009).

3. Eurostat ESA 1995- European System of Accounts (1996).

4. Georganta, Z. "Economic Crisis in Greece within the Periphery of Eurozone", Seminar organized by the Students' Union at the University of Macedonia, Thessaloniki, 23 March 2011.

5. Eurostat Manual on Government Deficit and Debt (2002, 2010).
6. Georganta, Z. "The Systemic Functioning of Innovation in the New Economy: A Concept-Mapping Approach", Scientific Annals, University of Macedonia, Thessaloniki, Greece (2005).

7. Eurostat (2000-2009) Annual Accounts by Institutional Sector, Greece.

8. Eurostat Reporting of Government Deficits and Debt Levels, Greece (13 April) (2011).

9. European Central Bank Fiscal Data Revisions in Europe, Working Paper 1342 (May) (2011). 
Z.Georganta /Journal of Engineering Science and Technology Review X (X) (2012) XX-XX

10. Eurostat-ELSTAT EDP Consolidated Inventory of Sources and

Methods, Greece (April) (2011). 